\title{
Structural basis for telmisartan-mediated partial activation of PPAR gamma
}

\author{
Yasushi Amano, Tomohiko Yamaguchi, Kazuki Ohno, Tatsuya Niimi, Masaya Orita, Hitoshi Sakashita \\ and Makoto Takeuchi \\ Telmisartan, a selective angiotensin II type 1 receptor blocker, has recently been shown to act as a partial agonist for peroxisome \\ proliferator-activated receptor gamma (PPAR $\gamma$ ). To understand how telmisartan partially activates PPAR $\gamma$, we determined the \\ ternary complex structure of PPAR $\gamma$, telmisartan, and a coactivator peptide from steroid receptor coactivator-1 at a resolution \\ of $2.18 \AA$. Crystallographic analysis revealed that telmisartan exhibits an unexpected binding mode in which the central \\ benzimidazole ring is engaged in a non-canonical-and suboptimal-hydrogen-bonding network around helix 12 (H12). This \\ network differs greatly from that observed when full-agonists bind with PPAR $\gamma$ and prompt high-coactivator recruitment through \\ $\mathrm{H} 12$ stabilized by multiple hydrogen bonds. Binding with telmisartan results in a less stable $\mathrm{H} 12$ that in turn leads to \\ attenuated coactivator binding, thus explaining the mechanism of partial activation. \\ Hypertension Research (2012) 35, 715-719; doi:10.1038/hr.2012.17; published online 23 February 2012
}

Keywords: angiotensin II type 1 receptor blockers; partial agonist; peroxisome proliferator-activated receptor; telmisartan; X-ray crystallography

\section{INTRODUCTION}

Angiotensin II is a physiologically active major effector of the reninangiotensin system. Angiotensin II mediates several biological functions in the kidney, heart and blood vessels through interaction with angiotensin II type 1 receptor. ${ }^{1,2}$ Therefore, inhibition of the reninangiotensin system by angiotensin II type 1 receptor blockers (ARBs) may be a therapeutic target for organ protection in patients with hypertension. ${ }^{3-5}$ Although ARBs are known to lower blood pressure, this ability depends on the specific ARB administered. ${ }^{6,7}$ A recent meta-analysis demonstrated that telmisartan is the ARB that reduces blood pressure, the most in patients with essential hypertension. ${ }^{7}$ Previously, we investigated the molecular basis of angiotensin II type 1 receptor inhibition by telmisartan using a molecular simulation and proposed a unique 'delta lock' structure for telmisartan that may be responsible for its high-binding affinity to angiotensin II type 1 receptor, thereby leading to its superiority over other ARBs in halting cardiovascular disease in patients with hypertension. ${ }^{8}$

Recently a subgroup of ARBs was reported to induce peroxisome proliferator-activated receptor-gamma (PPAR $\gamma$ ) activity, among which telmisartan shows the strongest ability. ${ }^{9,10}$ PPAR $\gamma$ is the most abundant isoform in adipose tissue and has an important role in the regulation of insulin sensitivity. ${ }^{11}$ Thiazolidinediones, such as pioglitazone or rosiglitazone, are highly affinitive full agonists of PPAR $\gamma$ and are currently used to treat type-2 diabetes. ${ }^{12}$ However, although thiazolidinediones are known to improve insulin sensitivity, glucose tolerance and lipid profile, their use has also been associated with adverse side effects such as weight gain, edema and renal-fluid retention. As a result of these clinical observations, emphasis has shifted to the development of new PPAR $\gamma$ ligands that retain metabolic efficacy without exerting adverse effects.

Telmisartan has recently been shown to behave like a selective $\operatorname{PPAR} \gamma$ modulator, ${ }^{9}$ a promising new type of ligand that either activates only a subset of the functions induced by cognate ligands, or acts in a cell-type-selective manner. ${ }^{13}$ Given that this drug functions as both a strong ARB and an selective PPAR $\gamma$ modulator, telmisartan is expected to target cardiovascular disease and diabetes mellitus, two closely associated conditions, with improved safety profiles in hypertensive patients. Indeed, a number of clinical and experimental studies have already been conducted, which provide evidence for the beneficial effects of telmisartan in cases of type 2 diabetes, as well as metabolic syndrome and obesity. ${ }^{14-20}$

Although the molecular mechanism required for the selective PPAR $\gamma$ modulator phenotype is still unknown, partial agonism is assumed to be a typical and essential characteristic of selective PPAR $\gamma$ modulator. ${ }^{9,13}$ Telmisartan exhibits this critical feature, ${ }^{9}$ and here we describe a crystal structure of human PPAR $\gamma$ in complex with telmisartan that clarifies the mechanism of partial agonism.

\section{METHODS}

Crystallization

The human PPAR $\gamma$ ligand-binding domain (LBD) (225-505) was expressed in E. coli as an N-terminal His-tagged protein. Affinity purification was performed 
with a $\mathrm{Ni}^{2+}$-coupled sepharose and the His-tag was removed by incubation with thrombin. Further purification was performed by ion exchange chromatography and gel filtration. The purified protein was concentrated to $16 \mathrm{mg} \mathrm{ml}^{-1}$ and incubated with telmisartan (isolated and purified from Micardis tablets) and a short peptide from human steroid receptor coactivator-1 (SRC1) (residues 685-700, ERHKILHRLLQEGSPS) for $1 \mathrm{~h}$ at final respective concentrations of 0.5 and $1 \mathrm{~mm}$. The solution was mixed with an equal volume of $0.1 \mathrm{M}$ Tris- $\mathrm{HCl}(\mathrm{pH} 7.0)$ and $0.8 \mathrm{M}$ sodium citrate tribasic dihydrate, and crystallized using sitting drop-vapor diffusion at $293 \mathrm{~K}$. Thick plate-like crystals appeared after $3-5$ days.

\section{Data collection and structure determination}

For data collection, crystals were transferred into cryoprotectant solution containing 30\% (v/v) glycerol and flash frozen at $100 \mathrm{~K}$. Data were collected at the Photon Factory AR-NE3A beamline (Tsukuba, Japan) and processed with HKL2000. ${ }^{21}$ The structure of human PPAR $\gamma$ LBD was solved by molecular replacement using MOLREP ${ }^{22,23}$ against an existing in-house structure of the human $\operatorname{PPAR} \gamma$ LBD. Crystals belonged to the orthorhombic space group $\mathrm{P} 2{ }_{1} 2{ }_{1} 2$, with cell axes of $\mathrm{a}=132.9 \AA$, $\mathrm{b}=53.5 \AA$ and $\mathrm{c}=53.9 \AA$. Data were refined by REFMAC software, ${ }^{24,25}$ which carried out rigid body and restrained refinement. An electron density difference map was used to place the ligand in real space refinement. Manual rebuilding of protein was done with Coot. ${ }^{26,27}$ The final structure consisted of the LBD except the region between residues 263 and 272 , the coactivator peptide (residues 686-696), and 47 water molecules. Data collection and refinement statistics are given in Supplementary Table 1 . The coordinates for the complexes described here have been deposited in the Protein Data Bank (PDB ID: 3VN2).

\section{RESULTS AND DISCUSSION}

\section{Structure of the PPAR $\gamma$ complexed with telmisartan}

To understand how telmisartan activates $\operatorname{PPAR} \gamma$, we crystallized the complex formed by the PPAR $\gamma$ LBD and telmisartan using a method similar to that previously employed on complexes formed between the LBD and other agonists (data not shown). Although we obtained plate-like crystals that belonged to space group $C 2$ from the solution containing PPAR $\gamma$ and telmisartan and found lattices similar to those found when PPAR $\gamma$ LBD formed complexes with other agonists, ${ }^{28-30}$ we did not observe telmisartan in the determined structure.
To stabilize the formation of the complex and to make new interfaces for crystal packing, a short peptide derived from the PPAR $\gamma$ activator SRC1 was designed based on the ternary complex structure of PPAR $\gamma .{ }^{29}$ As expected, when the peptide was added to the mixture containing PPAR $\gamma$ and telmisartan, an apparently new crystal precipitated from the solution, and its structure was subsequently analyzed by X-ray diffraction. The SRC1 peptide provided an interface with adjacent molecules in the crystal, and telmisartan was observed in the Fo-Fc electron density difference map after both rigid body and first restrained refinement.

Finally, we determined the crystal structure of PPAR $\gamma$ with telmisartan and the SRC1 peptide at a resolution of $2.18 \AA$. The overall fold was almost identical to previously determined apo and complex structures, ${ }^{28-30}$ and comprised of 12 helices (H1-H12) and a small $\beta$-sheet region of four strands (Figure 1a). We superposed $\mathrm{C} \alpha$ atoms from the structure of PPAR $\gamma$ with telmisartan onto those from the structure with rosiglitazone (PDB ID: 2PRG), ${ }^{29}$ 2-BABA (PDB ID: $1 \mathrm{WM} 0)^{30}$ and the apo structure (PDB ID: $\left.1 \mathrm{PRG}\right),{ }^{29}$ and calculated root mean square deviations. The root mean square deviations were $0.64 \AA$ for rosiglitazone, $0.69 \AA$ for 2 -BABA and $0.93 \AA$ for the apo structure.

\section{Binding mode of telmisartan in the PPAR $\gamma$}

The ligand-binding site of the PPAR $\gamma$ LBD is a large, Y-shaped cavity with a volume around $1400 \AA^{3}$ and consists of three branches (Figure 1a). ${ }^{31}$ Branch I, surrounded by H3, H5, H11 and H12, shows mainly hydrophilic character and provides an activation function-2 surface. The hydrophilic head group of rosiglitazone occupies this branch and forms a hydrogen-bonding network with key residues Ser289, His323, Tyr327, His449 and Tyr473. ${ }^{29}$ Branch II is a hydrophobic cavity, formed by $\mathrm{H}_{2}^{\prime}, \mathrm{H} 3, \mathrm{H} 6, \mathrm{H} 7$ and the $\beta$-sheet region. Branch III consists of hydrophobic and hydrophilic residues of $\mathrm{H} 2, \mathrm{H} 3$ and the $\beta$-sheet region. Some compounds such as farglitazar induce the slide of Phe363 side chain, resulting in the additional region (branch I'), perpendicular to branch I between $\mathrm{H} 3$ and $\mathrm{H} 7 .^{28}$

To our knowledge, three binding modes of telmisartan with PPAR $\gamma$ have been proposed by docking simulations. In the first mode, two
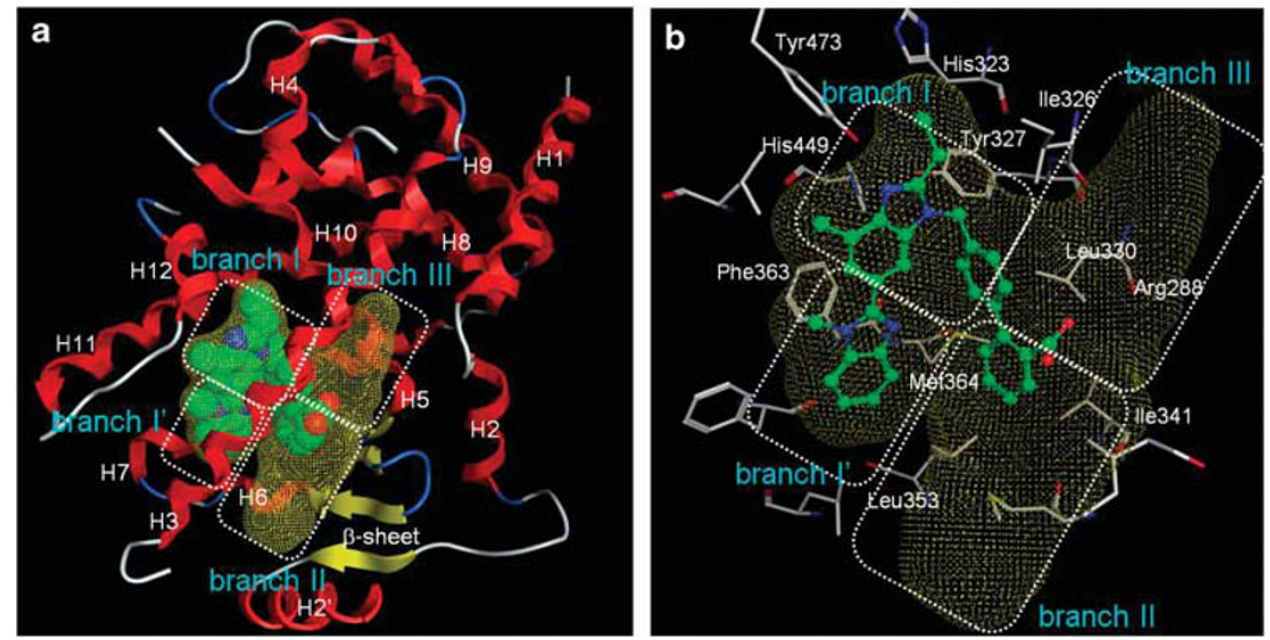

Figure 1 Complex structure of PPAR $\gamma$ with telmisartan. (a) The overall complex structure. The ligand-binding cavity composed of four branches is shown in yellow dots. (b) The ligand-binding pocket of PPAR $\gamma$ in the presence of telmisartan. Important residues involved in the ligand-protein interaction are indicated in white. 
benzimidazole rings occupy branch II, the central benzene ring and the propyl group fill branch III, and branch I is nearly empty. ${ }^{9,32,33}$ In the second mode, the biphenyl moiety and the central benzimidazole ring occupy branches II and III, respectively, and the distal benzimidazole ring points into branch I but makes no hydrogen bonds. ${ }^{34}$ In the third mode, the biphenyl moiety and the central benzimidazole ring fill branch I' and I, respectively, whereas the distal benzimidazole ring occupies branch II. This mode also predicts no hydrogen-bonding interaction around $\mathrm{H} 12 .{ }^{35}$

The binding mode observed in the crystal structure we have determined adopts a U-shaped conformation around Cys 285 and is distinct from these three predicted modes (Figure 1b). The central benzimidazole ring from telmisartan occupies branch I, and its N3' nitrogen forms a hydrogen bond with H12-residue Tyr473. The His323 side chain is pushed out from the position it occupies in other complex structures, and the propyl moiety fills the newly formed region. This interaction is characteristic of telmisartan and is not observed for any other complex structure deposited in PDB except one. ${ }^{36}$

Substitution of this propyl moiety for a shorter alkyl chain has been found to attenuate activity, ${ }^{37}$ indicating the importance of this interaction related with the flip of His 323 . The benzene ring of the central benzimidazole ring is involved in T-shaped $\pi$-stacking interaction with His449, the distal benzimidazole group fills branch I' with $\pi-\pi$ stacking interaction with Phe363 in H9, and the $1^{\prime}$-methyl group contacts Phe282 via Van der Waals interaction. This interaction explains the decrease in activity caused by deletion of the $1^{\prime}$-methyl group. ${ }^{37}$ The biphenyl moiety exists in branch II and III, and exhibits hydrophobic interaction with Ile326, Leu330, Ile341, Leu353 and Met364, from H5 to H7. Although the carboxylate group forms hydrogen bonds with Ser342 and Arg288 in the previous docking model, ${ }^{34}$ in our crystal structure it does not make hydrogen bonds with any residues in branch II. This dispensability of carboxylate is consistent with the previous SAR analysis of telmisartan. ${ }^{37}$
Molecular basis of PPAR $\gamma$ partial activation mechanism through unique binding mode of telmisartan

Previous structural studies of PPAR $\gamma$ suggested that the activation mechanism of full agonists and partial agonists are different from each other. Full-agonistic activity is thought to result from several factors that stabilize $\mathrm{H} 12$ in the proper position, prompt coactivator peptide binding, and are observed in the structure of all complexes comprised of PPAR $\gamma$. These include multiple intermolecular hydrogen bonds between carboxylic acid, or its bioisostere, and amino-acid residues Ser289, His323, His449 and Tyr473, as well as intramolecular hydrogen bonds among these four residues and Tyr327. ${ }^{38}$ In addition, a certain level of occupation in branches II or III is required to increase affinity.

In contrast, the complexes comprised of PPAR $\gamma$ and partial-agonists lack this hydrogen-bond network, or else it is suboptimal. This produces an unstable or unfavorable conformation for coactivator binding. Instead, partial-agonists display hydrophobic interaction in branch II or III, leading to the stabilization of $\mathrm{H} 3$ and the $\beta$-sheet region rather than H12. ${ }^{38}$ A hydrogen bond with Ser342 at the border of two branches is observed for some partial agonists to reinforce this hydrophobic interaction. This H12-independent activation mechanism is characteristic of partial agonists.

The partial activation mechanism of telmisartan can be explained by the attenuation of the hydrogen-bonding network around H12, derived from the unique biding mode described here (Figures $2 \mathrm{a}-\mathrm{c}$ ). Telmisartan induces only one intermolecular hydrogen bond (Tyr473), whereas full agonists rosiglitazone and farglitazar form three (Ser289, His323 and Tyr473) ${ }^{29}$ and four (Ser289, His323, His449 and Tyr473) bonds, respectively. ${ }^{28}$ Further, the propyl group pushes His 323 out from the position it occupies in full-agonist complexes. These factors give rise to the non-canonical hydrogen-bonding network around H12, which hinders recruitment of coactivator peptides. In fact, partial agonism by telmisartan is only weakly correlated with H12 stabilization. PPAR $\gamma$ activation was selectively reduced by a
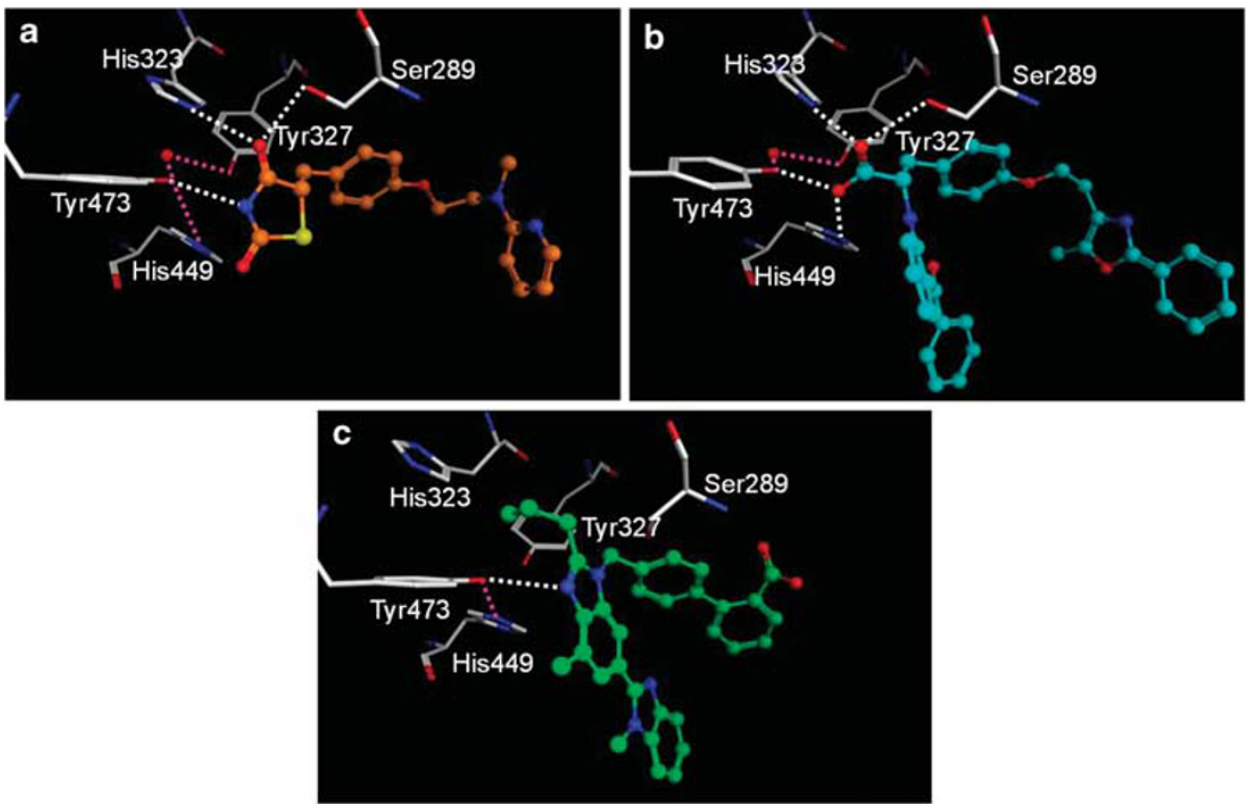

Figure 2 Comparison of the hydrogen-bonding network around H12 among complex structures. White dotted line: intermolecular hydrogen bonds between ligands and PPAR $\gamma$. Purple dotted line: hydrogen bonds observed in PPAR $\gamma$ water molecules. Rosiglitazone is colored orange (a), farglitazar is cyan (b) and telmisartan is green (c). 


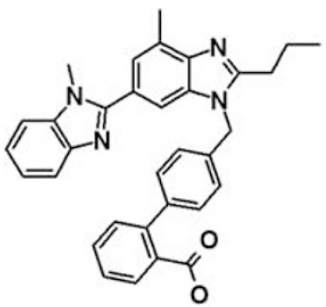

Telmisartan

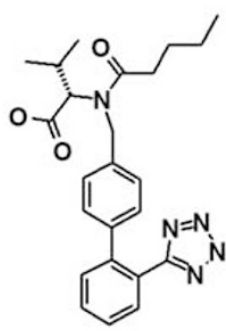

Valsartan

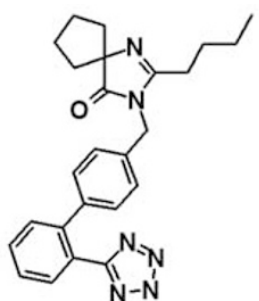

Irbesartan

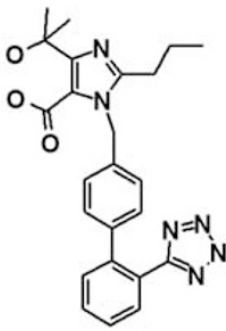

Olmesartan

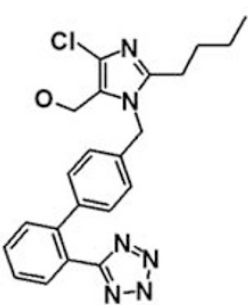

Losartan

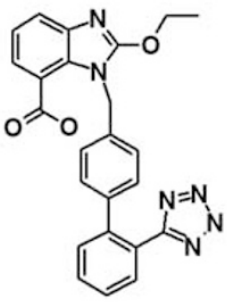

Candesartan

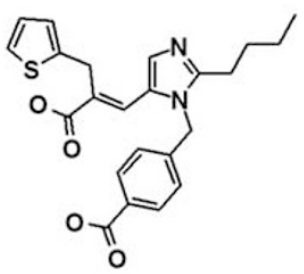

Eprosartan

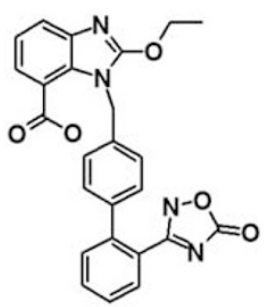

Azilsartan

Figure 3 Chemical structures of representative ARBs.

mutation at Tyr473 when complexed with full agonists troglitazone and pioglitazone, but not with telmisartan. ${ }^{39}$

Although the binding mode of telmisartan is distinct from that of rosiglitazone, the interaction between the SRC1-derived peptide and PPAR $\gamma$ in the ternary complex with telmisartan is almost identical to that with rosiglitazone, in which the 'LXXLL' motif in SRC1 that is essential for the interaction is packed between Lys301 and Glu471 on PPAR $\gamma .{ }^{29}$ This strongly suggests that the partial agonism observed with telmisartan does not arise from the stabilization of a suboptimal conformation for coactivator binding, but rather from the reduced population of optimal conformations in dynamic behavior that are difficult to detect in the crystal structures. Previous structural analysis of PPAR $\gamma$ with partial agonists has also revealed that the binding modes of coactivator-derived peptides are virtually identical to that seen for PPAR $\gamma$ with rosiglitazone. ${ }^{30,40}$ Although some partial agonists including telmisartan are known to exhibit selectivity for coactivators, the reason behind this selectivity cannot be determined by observing complex structures. It is possible that selectivity is generated through subtle differences in dynamics.

Structural insight into the interaction of PPAR $\gamma$ with other ARBs Telmisartan is the most potent activator of PPAR $\gamma$ among ARBs, followed by irbesartan and losartan. Valsartan, candesartan, olmesartan and eprosartan produce minimal activation. ${ }^{9,10}$ Reports show that telmisartan is the only ARB that activates PPAR $\gamma$ at concentrations lower than can be achieved in plasma with conventional oral dosing $\left(1-5 \mu \mathrm{moll}^{-1}\right) .{ }^{9}$ To determine the structure responsible for the lower efficiency exhibited by other ARBs, we examined whether or not these can bind to the ligand-binding cavity of PPAR $\gamma$ with the assumption that the common structure of ARBs, consisting of a biphenyl moiety bearing a carboxylic or tetrazole group and an imidazole ring with an alkyl chain, occupies the same position as that of telmisartan (see Figure 3 for the structures of ARBs).
Results showed that these other ARBs did not bind well to the ligandbinding cavity, and further indicate that this was because of structural differences between the benzene ring of the central benzimidazole ring of telmisartan and the corresponding parts of other ARBs. This benzene ring is packed in a hydrophobic environment between His449 and Cys285, which is a narrow region that can accommodate only planar groups. As a result, this region seems to be unable to accommodate bulky groups that are present on valsartan, olmesartan and eprosartan. This hydrophobic region is also unfavorable to highly-hydrophilic groups such as a carboxylic acid that is involved in valsartan, olmesartan, eprosartan, candersatan, and EXP3174, the major active metabolite of losartan. Further, this ring interacts with His449 via T-shaped $\pi$-stacking, whereas most other ARBs do not. Although candesartan and azilsartan are exceptions, they also fail to exhibit the same binding mode as that of telmisartan because of a steric clash between biphenyl and carboxylic groups. These structural investigations allow an assessment of PPAR $\gamma$ activating properties of other ARBs.

In conclusion, we determined the ternary complex structure of PPAR $\gamma$, telmisartan and an SRC1 peptide. Telmisartan exhibits an unexpected and unique binding mode that is distinct from previously predicted models. Partial agonism by telmisartan can be ascribed to the suboptimal hydrogen-bonding network around H12, which is induced by the characteristic structure of telmisartan, specifically the central propyl benzimidazole group. This group is also a structural determinant that discriminates telmisartan from weak ARBs. Ours is the first report that elucidates the partial activation mechanism of PPAR $\gamma$ by ARB at the atomic level.

\section{ACKNOWLEDGEMENTS}

We thank Drs Hirotoshi Kakuta and Hiroyuki Okumura for their insightful discussions. 
1 de Gasparo M, Catt KJ, Inagami T, Wright JW, Unger T. International Union of Pharmacology. XXIII. The angiotensin II receptors. Pharmacol Rev 2000; 52 : 415-472.

2 Mehta PK, Griendling KK. Angiotensin II cell signaling: physiological and pathological effects in the cardiovascular system. Am J Physiol Cell Physiol 2007; 292. C82-C97.

3 Blood Pressure Lowering Treatment Trialists' Collaboration. Blood pressure-dependent and independent effects of agents that inhibit the renin-angiotensin system. $J$ Hypertens 2007; 25: 951-958.

4 Brenner BM, Cooper ME, de Zeeuw D, Keane WF, Mitch WE, Parving H-H, Remuzzi G, Snapinn SM, Zhang Z, Shahinfar S. Effects of losartan on renal and cardiovascular outcomes in patients with Type 2 diabetes and nephropathy. N Engl J Med 2001; 345: 861-869.

5 McMurray JJV, Östergren J, Swedberg K, Granger CB, Held P, Michelson EL, Olofsson B, Yusuf S, Pfeffer MA. Effects of candesartan in patients with chronic heart failure and reduced left-ventricular systolic function taking angiotensin-converting-enzyme inhibitors: the CHARM-added trial. Lancet 2003; 362: 767-771.

6 Lacourciere Y, Krzesinski JM, White WB, Davidai G, Schumacher H. Sustained anti hypertensive activity of telmisartan compared with valsartan. Blood Press Monit 2004; 9: 203-210.

7 Nixon RM, Müller E, Lowy A, Falvey H. Valsartan vs. other angiotensin II receptor blockers in the treatment of hypertension: a meta-analytical approach. Int J Clin Pract 2009; 63: 766-775.

8 Ohno K, Amano Y, Kakuta H, Niimi T, Takakura S, Orita M, Miyata K, Sakashita H, Takeuchi M, Komuro I, Higaki J, Horiuchi M, Kim-Mitsuyama S, Mori Y, Morishita R, Yamagishi S-I. Unique 'delta lock' structure of telmisartan is involved in its strongest binding affinity to angiotensin II type 1 receptor. Biochem Biophys Res Commun 2011; 404: 434-437.

9 Benson SC, Pershadsingh HA, Ho Cl, Chittiboyina A, Desai P, Pravenec M, Qi NN, Wang JM, Avery MA, Kurtz TW. Identification of telmisartan as a unique angiotensin II receptor antagonist with selective PPAR gamma-modulating activity. Hypertension 2004; 43: 993-1002.

10 Schupp M, Janke J, Clasen R, Unger T, Kintscher U. Angiotensin Type 1 receptor blockers induce peroxisome proliferator-activated receptor $\gamma$ activity. Circulation 2004 109: 2054-2057.

11 Picard F, Auwerx J. PPAR $\gamma$ and glucose homeostasis. Annu Rev Nutr 2002; 22 167-197.

12 Staels B, Fruchart J-C. Therapeutic roles of peroxisome proliferator-activated receptor agonists. Diabetes 2005; 54: 2460-2470.

13 Berger JP, Petro AE, Macnaul KL, Kelly LJ, Zhang BB, Richards K, Elbrecht A, Johnson BA, Zhou G, Doebber TW, Biswas C, Parikh M, Sharma N, Tanen MR, Thompson GM, Ventre J, Adams AD, Mosley R, Surwit RS, Moller DE. Distinct properties and advantages of a novel peroxisome proliferator-activated protein $\gamma$ selective modulator. Mol Endocrinol 2003; 17: 662-676.

14 de Luis DA, Conde R, Gonzalez-Sagrado M, Aller R, Izaola O, Duenas A, Castrillon JLP, Romero E. Effects of telmisartan vs. olmesartan on metabolic parameters, insulin resistance and adipocytokines in hypertensive obese patients. Nutr Hosp 2010; 25: 275-279.

15 Derosa G, Fogari E, D’Angelo A, Cicero AFG, Salvadeo SAT, Ragonesi PD, Ferrari I, Gravina A, Fassi R, Fogari R. Metabolic effects of telmisartan and irbesartan in type 2 diabetic patients with metabolic syndrome treated with rosiglitazone. J Clin Pharm Ther 2007; 32: 261-268.

16 Fujimoto M, Masuzaki H, Tanaka T, Yasue S, Tomita T, Okazawa K, Fujikura J, Chusho H, Ebihara K, Hayashi T, Hosoda K, Nakao K. An angiotensin II AT1 receptor antagonist, telmisartan augments glucose uptake and GLUT4 protein expression in 3T3-L1 adipocytes. FEBS Lett 2004; 576: 492-497.

17 Miura Y, Yamamoto N, Tsunekawa S, Taguchi S, Eguchi Y, Ozaki N, Oiso Y. Replacement of valsartan and candesartan by telmisartan in hypertenitive patients with type 2 diabetes. Diabetes Care 2005; 28: 757-758.

18 Mori Y, Itoh Y, Tajima N. Angiotensin II receptor blockers downsize adipocytes in spontaneously Type 2 diabetic rats with visceral fat obesity. Am J Hypertens 2007; 20: 431-436.

19 Negro R, Formoso G, Hassan $\mathrm{H}$. The effects of irbesartan and telmisartan on metabolic parameters and blood pressure in obese, insulin resistant, hypertensive patients. J Endocrinol Investig 2006; 29: 957-961.
20 Shimabukuro M, Tanaka H, Shimabukuro T. Effects of telmisartan on fat distribution in individuals with the metabolic syndrome. J Hypertens 2007; 25: 841-848.

21 Otwinowski Z, Minor W. Processing of X-ray diffraction data collected in oscillation mode. In: Abelson JN, Simon MI, Carter CW, Jr., Sweet RM (eds). Methods in Enzymology Vol. 276. Academic Press, San Diego, CA, 1997, pp 307-326.

22 Vagin A, Teplyakov A. MOLREP: an automated program for molecular replacement. J Appl Crystal 1997; 30: 1022-1025.

23 Vaguine AA, Richelle J, Wodak SJ. SFCHECK: a unified set of procedures for evaluating the quality of macromolecular structure-factor data and their agreement with the atomic model. Acta Crystallogr Sect D 1999; 55 (Pt 1): 191-205.

24 Collaborative Computational Project N. The CCP4 suite: programs for protein crystallography. Acta Crystallogr Sect D 1994; 50: 760-763.

25 Murshudov GN, Vagin AA, Lebedev A, Wilson KS, Dodson EJ. Efficient anisotropic refinement of macromolecular structures using FFT. Acta Crystallogr Sect D 1999; 55: 247-255.

26 Emsley P, Cowtan K. Coot: model-building tools for molecular graphics. Acta Crystallogr Sect D 2004; 60: 2126-2132.

27 Emsley P, Lohkamp B, Scott WG, Cowtan K. Features and development of Coot. Acta Crystallogr Sect D 2010; 66: 486-501.

28 Gampe RT, Montana VG, Lambert MH, Miller AB, Bledsoe RK, Milburn MV, Kliewer SA, Willson TM, Xu HE. Asymmetry in the PPAR [gamma]/RXR [alpha] crystal structure reveals the molecular basis of heterodimerization among nuclear receptors. Mol Cell 2000; 5: 545-555.

29 Nolte RT, Wisely GB, Westin S, Cobb JE, Lambert MH, Kurokawa R, Rosenfeld MG, Willson TM, Glass CK, Milburn MV. Ligand binding and co-activator assembly of the peroxisome proliferator-activated receptor-[gamma]. Nature 1998; 395: 137-143.

30 Östberg T, Svensson S, Selén G, Uppenberg J, Thor M, Sundbom M, Sydow-Bäckman $M$, Gustavsson A-L, Jendeberg L. A new class of peroxisome proliferator-activated receptor agonists with a novel binding epitope shows antidiabetic effects. J Biol Chem 2004; 279: 41124-41130.

31 Markt P, Schuster D, Kirchmair J, Laggner C, Langer T. Pharmacophore modeling and parallel screening for PPAR ligands. J Comput Aided Mol Des 2007; 21: 575-590.

32 Chittiboyina A, Mizuno C, Desai P, Patny A, Kurtz T, Pershadsingh H, Speth R, Karamyan V, Avery M. Design, synthesis, and docking studies of novel telmisartanglitazone hybrid analogs for the treatment of metabolic syndrome. Med Chem Res 2009; 18: 589-610.

33 Mizuno C, Chittiboyina A, Patny A, Kurtz T, Pershadsingh H, Speth R, Karamyan V, Avery M. Design, synthesis, and docking studies of telmisartan analogs for the treatment of metabolic syndrome. Med Chem Res 2009; 18: 611-628.

34 Goebel M, Wolber G, Markt P, Staels B, Unger T, Kintscher U, Gust R. Characterization of new PPAR [gamma] agonists: Benzimidazole derivatives-importance of positions 5 and 6, and computational studies on the binding mode. Bioorg Med Chem 2010; 18: 5885-5895.

35 Marshall T, Lee R, Marshall F. Common angiotensin receptor blockers may directly modulate the immune system via VDR, PPAR and CCR2b. Theor Biol Med Model 2006; 3. 1 .

36 Trump RP, Cobb JE, Shearer BG, Lambert MH, Nolte RT, Willson TM, Buckholz RG, Zhao SM, Leesnitzer LM, lannone MA, Pearce KH, Billin AN, Hoekstra WJ. Co-crystal structure guided array synthesis of PPAR [gamma] inverse agonists. Bioorg Med Chem Lett 2007; 17: 3916-3920.

37 Goebel M, Clemenz M, Staels B, Unger T, Kintscher U, Gust R. Characterization of new PPAR $\gamma$ agonists: analysis of telmisartan's structural components. Chem Med Chem 2009; 4: 445-456.

38 Bruning JB, Chalmers MJ, Prasad S, Busby SA, Kamenecka TM, He Y, Nettles KW, Griffin PR. Partial agonists activate PPAR [gamma] using a Helix 12 independent mechanism. Structure 2007; 15: 1258-1271.

39 Tagami T, Yamamoto H, Moriyama K, Sawai K, Usui T, Shimatsu A, Naruse M. A selective peroxisome proliferator-activated receptor-\{gamma\} modulator, telmisartan, binds to the receptor in a different fashion from thiazolidinediones. Endocrinology 2009; 150: 862-870.

40 Hopkins CR, O'Neil SV, Laufersweiler MC, Wang Y, Pokross M, Mekel M, Evdokimov A, Walter R, Kontoyianni M, Petrey ME, Sabatakos G, Roesgen JT, Richardson E, Demuth Jr TP. Design and synthesis of novel N-sulfonyl-2-indole carboxamides as potent PPAR$\gamma$ binding agents with potential application to the treatment of osteoporosis. Bioorg Med Chem Lett 2006; 16: 5659-5663.

Supplementary Information accompanies the paper on Hypertension Research website (http://www.nature.com/hr) 